\title{
Cardiovascular effects of total intravenous anesthesia using ketamine-medetomidine- propofol (KMP-TIVA) in horses undergoing surgery
}

\author{
Mohammed Ahmed UMAR ${ }^{1)}$, Sho FUKUI ${ }^{3)}$, Kodai KAWASE ${ }^{3)}$, Takaharu ITAMI $^{2)}$ and Kazuto YAMASHITA ${ }^{3) *}$ \\ ${ }^{1)}$ Department of Veterinary Surgery and Theriogenology, Faculty of Veterinary Medicine, University of Maiduguri, Maiduguri, Borno \\ State, Nigeria \\ 2) Veterinary Teaching Hospital, Graduate School of Veterinary Medicine, Hokkaido University, Sapporo, Hokkaido 060-0819, Japan \\ ${ }^{3)}$ Department of Small Animal Clinical Sciences, School of Veterinary Medicine, Rakuno Gakuen University, Ebetsu, Hokkaido 069-8501, \\ Japan
}

(Received 15 July 2014/Accepted 27 October 2014/Published online in J-STAGE 19 November 2014)

ABSTRACT. Cardiovascular effects of total intravenous anesthesia using ketamine-medetomidine-propofol drug combination (KMP-TIVA) were determined in 5 Thoroughbred horses undergoing surgery. The horses were anesthetized with intravenous administration (IV) of ketamine $(2.5 \mathrm{mg} / \mathrm{kg})$ and midazolam $(0.04 \mathrm{mg} / \mathrm{kg})$ following premedication with medetomidne $(5 \mu \mathrm{g} / \mathrm{kg}, \mathrm{IV})$ and artificially ventilated. Surgical anesthesia was maintained by controlling propofol infusion rate (initially $0.20 \mathrm{mg} / \mathrm{kg} / \mathrm{min}$ following an IV loading dose of $0.5 \mathrm{mg} / \mathrm{kg}$ ) and constant rate infusions of ketamine $(1 \mathrm{mg} / \mathrm{kg} / \mathrm{hr})$ and medetomidine $(1.25 \mu \mathrm{g} / \mathrm{kg} / \mathrm{hr})$. The horses were anesthetized for $175 \pm 14 \mathrm{~min}$ (range from 160 to $197 \mathrm{~min}$ ). Propofol infusion rates ranged from 0.13 to $0.17 \mathrm{mg} / \mathrm{kg} / \mathrm{min}$, and plasma concentration (Cpl) of propofol ranged from 11.4 to $13.3 \mu \mathrm{g} / \mathrm{m} l$ during surgery. Cardiovascular measurements during surgery remained within clinically acceptable ranges in the horses (heart rate: 33 to 37 beats $/ \mathrm{min}$, mean arterial blood pressure: 111 to $119 \mathrm{mmHg}$, cardiac index: 48 to $53 \mathrm{ml} / \mathrm{kg} / \mathrm{min}$, stroke volume: 650 to $800 \mathrm{ml} /$ beat and systemic vascular resistance: 311 to $\left.398 \mathrm{dynes} / \mathrm{sec} / \mathrm{cm}^{5}\right)$. The propofol Cpl declined rapidly after the cessation of propofol infusion and was significantly lower at $10 \min (4.5 \pm 1.5 \mu \mathrm{g} / \mathrm{m} l)$, extubation $(4.0 \pm 1.2 \mu \mathrm{g} / \mathrm{m} l)$ and standing $(2.4 \pm 0.9 \mu \mathrm{g} / \mathrm{m} l)$ compared with the $\mathrm{Cpl}$ at the end of propofol administration $(11.4 \pm 2.7 \mu \mathrm{g} / \mathrm{m} l)$. All the horses recovered uneventfully and stood at $74 \pm$ $28 \mathrm{~min}$ after the cessation of anesthesia. KMP-TIVA provided satisfactory quality and control of anesthesia with minimum cardiovascular depression in horses undergoing surgery.

KEY WORDS : cardiovascular function, equine, ketamine, medetomidine, propofol

doi: 10.1292/jvms.14-0370; J. Vet. Med. Sci. 77(3): 281-288, 2015

General anesthesia for prolonged duration surgical procedures in horses is generally accomplished by administering inhalant anesthetics. The inspired concentration of inhalant anesthetics required in providing a surgical plane of anesthesia frequently contributes to intraoperative hypotension and hypoventilation [28]. Some studies have suggested that TIVA in horses produces better cardiopulmonary values than inhalation anesthesia $[1,2,19,31]$.

A variety of TIVA techniques have been investigated for short surgical procedures in horses [34]. The use of TIVA for longer surgical procedures has generally included combinations of centrally acting muscle relaxants (guaifenesin and midazolam), $\alpha_{2}$-adrenoceptor agonists or both in conjunction with ketamine [12, 19, 29, 35] and medetomidine-propofol drug combination with or without ketamine [3, 4, 30].

Propofol's rapid onset of action and short context-sensitive half-life are conductive to rapid recovery from anesthesia following short duration procedures [23]. Propofol, howev-

\footnotetext{
*Correspondence to: Yamashita, K., Department of Small Animal Clinical Sciences, School of Veterinary Medicine, Rakuno Gakuen University, Ebetsu, Hokkaido 069-8501, Japan.

e-mail: yamasita@rakuno.ac.jp

(C)2015 The Japanese Society of Veterinary Science

This is an open-access article distributed under the terms of the Creative Commons Attribution Non-Commercial No Derivatives (by-nc-nd) License $<$ http://creativecommons.org/licenses/by-nc-nd/3.0/>.
}

er, can produce marked cardiorespiratory depression and is considered unsatisfactory when used by itself for induction and maintenance of anesthesia in horses $[18,30]$. Combining propofol with various sedative and analgesic drugs could provide an alternative method for improving the quality and safety of anesthesia in horses and potentially decrease the total dose of drug required [4, 10, 17, 20, 30].

Towards this end, several studies have investigated and considered propofol drug combinations suitable for TIVA in horses for periods lasting longer than $2 \mathrm{hr}[1,3,4]$. The combination of ketamine-medetomidine-propofol for TIVA (KMP-TIVA) was demonstrated to provide better maintenance of surgical anesthesia and decreased the requirement of propofol compared to propofol infusion alone in horses [30]. Another study reported that cardiovascular function was preserved within acceptable values during extended KMP-TIVA in horses [31]. However, detailed evaluation of cardiovascular function has not been reported in horses undergoing a surgical procedure. Furthermore, propofol $\mathrm{Cpl}$ has not been examined in horses anesthetized or recovering from KMP-TIVA. The purpose of the study reported here was to determine cardiovascular effects of KMP-TIVA during surgery in horses.

\section{MATERIALS AND METHODS}

Animals: Five healthy Thoroughbred horses (3 mares and 
2 stallions; mean \pm SD weight was $482 \pm 53 \mathrm{~kg}$ [range, 428 to $564 \mathrm{~kg}$ ]; mean age was $11.2 \pm 8.4$ years [range, 2 to 18 years old]) were used for the present study. Food but not water was withheld from the horses for $12 \mathrm{hr}$ before anesthesia. Horses were cared for according to principles of the Guide for the Care and Use of Laboratory Animals prepared by Rakuno Gakuen University. The Animal Care and Use Committee of School of Veterinary Medicine, Rakuno Gakuen University approved the study (Approved No. 3-2003).

Anesthesia and surgical procedure: Each horse was premedicated with medetomidine (Domitor; Meiji Seika Co., Tokyo, Japan) (5 $\mu \mathrm{g} / \mathrm{kg}, \mathrm{IV})$ via a 14-gauge, $13.3-\mathrm{cm}$ catheter (BD Angiocath; Becton-Dickinson Sys Inc., Sandy, UT, U.S.A.) placed percutaneously into a jugular vein. Five minutes later, anesthesia was induced with midazolam (Midazolam injection 0.5\%; Fuji Seiyaku Co., Tokyo, Japan) $(0.04 \mathrm{mg} / \mathrm{kg}, \mathrm{IV})$ and ketamine (Ketalar 100; Sankyo Co., Tokyo, Japan) (2.5 mg/kg, IV). The horses were orotracheally intubated, positioned in left lateral recumbency on an inflated airbed surgical table and connected to a large animal circle anesthesia system that incorporated a ventilator (Mallard Medical ventilator Rachel Model 2800 L.A.A.V; Mallard Medical Inc., Redding, CA, U.S.A.) and breathed 100\% oxygen $(5 \mathrm{l} / \mathrm{min})$. A loading dose of propofol (Rapinovet; Schering-Plough Animal Health Co., Tokyo, Japan) (0.5 mg/ $\mathrm{kg}, \mathrm{IV})$ was administered to all the horses, and a constant rate infusion (CRI) of ketamine $(1 \mathrm{mg} / \mathrm{kg} / \mathrm{hr})$ and medetomidine $(1.25 \mu \mathrm{g} / \mathrm{kg} / \mathrm{hr})$ and propofol was started (KMP-TIVA); the CRI of the ketamine and medetomidine (KM) drug combination was administered by use of a syringe infusion pump (STC-521; Terumo Co., Tokyo, Japan). Propofol was administered with an infusion pump (Subratek 3030; JMS, Hiroshima, Japan): the infusion rate adjusted as needed to prevent response to surgical stimulation. The initial rate of propofol infusion was $0.2 \mathrm{mg} / \mathrm{kg} / \mathrm{min}$. The CRI of propofol was increased by $0.025 \mathrm{mg} / \mathrm{kg} / \mathrm{min}$ when spontaneous movement occurred. A bolus of propofol (200 mg, IV) was administered when the movement remained uncontrolled by increasing the infusion rate of propofol. The rate of propofol infusion was decreased by $0.025 \mathrm{mg} / \mathrm{kg} / \mathrm{min}$ when purposeful movement was not detected during surgery i.e. decreased in increments until the lowest effective level was reached.

Lactated Ringer's solution (Solulact; Terumo Co.) was administered IV at a rate of $10 \mathrm{ml} / \mathrm{kg} / \mathrm{hr}$ to all horses. The urinary bladder was catheterized to maintain an empty bladder during anesthesia. Breathing was controlled using intermittent positive pressure ventilation (IPPV) after induction to anesthesia and adjusted to maintain the partial pressure of arterial carbon dioxide $\left(\mathrm{PaCO}_{2}\right)$ at 40 to $50 \mathrm{mmHg}$ until the end of anesthesia. The respiratory rate was set at 6 breaths/ min, tidal volume at $15 \mathrm{~m} / / \mathrm{kg}$ and peak intra airway pressure of 20 to $25 \mathrm{cmH}_{2} \mathrm{O}$.

Following aseptic preparation of the operative site and instrumentation (mentioned later), the same person (K.Y.) performed the surgical translocations of the right carotid artery in all the horses. A $30 \mathrm{~cm}$ long skin incision was made immediately dorsal to the right jugular furrow in each horse at approximately $60 \mathrm{~min}$ after the induction of anesthesia. The right carotid artery was identified and surgically relocated to a subcutaneous position. The KMP-TIVA, monitoring and fluid administration were discontinued shortly after completing the carotid artery translocation surgery. The horses were transported to a $3.5 \mathrm{~m} \times 3.5 \mathrm{~m}$ padded recovery stall. The endotracheal tube was removed when horses regained the swallowing reflex. All horses recovered with assistance using head and tail ropes. Flunixin meglumine (Banamine 5\%; Dai Nippon Seiyaku Co., Osaka, Japan) (1 mg/kg, IV) and penicillin $\mathrm{G}$ procaine $\left(4 \times 10^{6} \mathrm{U} /\right.$ horse, IM) combined with dihydrostreptomycin sulfate (5 g/horse, IM) (Mycillinsol Meiji; Meiji Seika Co., Ltd.) were administered every $12 \mathrm{hr}$ for 3 days.

Instrumentations for measuring cardiorespiratory parameters: All horses were instrumented with vascular catheters for sampling arterial blood and measurement of hemodynamic data during the first 30 to $60 \mathrm{~min}$ of KMP-TIVA. The area over the right jugular furrow and the right metatarsal were clipped and prepared aseptically. An 18-gauge catheter (Supercath; Medikit Co., Tokyo, Japan) was placed in the right dorsal third of the metatarsal artery. An 8-french introducer (Exacta percutaneous sheath introducer 8Fr; Ohmeda, Swindon, U. K.) was placed in the right jugular vein, and a 9-french introducer (Exacta percutaneous sheath introducer 9Fr; Ohmeda) was placed in the right jugular vein $30 \mathrm{~cm}$ proximal to the 8-french introducer. A triple-lumen 7-french 100-cm Swan-Ganz ballooned-tipped thermistor catheter (Criti-Cath SP-5107; Ohmeda) was placed in the pulmonary artery via an 8 -french introducer and advanced into the jugular vein and into the pulmonary artery. Catheter position was confirmed by the characteristic pressure wave for each heart's chamber. An 8-french 100-cm catheter (Intervec super guiding catheter; Fuji Systems Co., Tokyo, Japan) was placed in the right atrium via the 9-french introducer. The distance between the tip of the Swan-Ganz catheter and the 8 -french catheter was adjusted to $40-50 \mathrm{~cm}$. The proximal end of the Swan-Ganz, right atrial and arterial catheters were connected to saline $(0.9 \% \mathrm{NaCl})$ solution-filled extension tubing to pressure transducers (CDX-A90; Cobe Laboratories, Tokyo, Japan) and a hemodynamic monitor (DS-5300; Fukuda Denshi, Tokyo, Japan). The transducers were positioned at the level of the heart before calibration.

Cardiorespiratory measurements: Cardiovascular measurements and arterial blood gas data were recorded every $20 \mathrm{~min}$ and during 2.5 to $3.0 \mathrm{hr}$ of anesthesia. Arterial blood pressure (ABP; mmHg), pulmonary artery pressure (PAP; $\mathrm{mmHg}$ ) and right atrial pressure (RAP; $\mathrm{mmHg}$ ) were measured by connecting the catheters placed in the dorsal metetarsal artery, pulmonary artery and right atrium, respectively, to pressure transducers and a hemodynamic monitor. Cardiac output $(\mathrm{CO} ; l / \mathrm{min})$ was measured by the thermodilution technique [22] using $40 \mathrm{ml}$ of $0^{\circ} \mathrm{C} 5 \%$ dextrose injected manually for approximately $2 \mathrm{sec}$ through an 8 -french catheter placed in the right atrium. The $\mathrm{CO}$ was measured at least 3 times, and the mean value was calculated. Heart rate (HR; beats/min), electrocardiogram (Apex-Base lead), ABP, PAP, RAP and CO were recorded at predetermined times. Cardiac index (CI; $\mathrm{m} l / \mathrm{kg} / \mathrm{min})$, stroke volume (SV; ml/beat) 
Table 1. Criteria for scoring the quality of anesthetic induction, transition to infusion, maintenance of anesthesia and recovery from anesthesia following TIVA in horses

\begin{tabular}{ll}
\hline Score & Criteria \\
\hline Anesthetic induction & \\
0 (Poor) & Ataxia and paddling; danger to horse and handler \\
1 (Fair) & Purposeful paddling with or without attempts to regain feet \\
2 (Satisfactory) & Ataxia with or without paddling \\
3 (Good) & Horse takes 1 or 2 steps before falling to ground; no paddling \\
4 (Excellent) & Horse sinks smoothly to the ground \\
\hline Transition to infusion & \\
0 (Poor) & Multiple incremental bolus IV doses (200 mg each) of propofol needed \\
1 (Fair) & One or 2 additional bolus IV doses of propofol needed during first 20 min \\
2 (Good) & Appeared to be in light plane of anesthesia; responded to a bolus IV injection of propofol \\
3 (Excellent) & Smooth transition; additional propofol injection not required \\
\hline Anesthetic maintenance \\
0 (Poor) & Multiple incremental IV bolus doses (200 mg each) of propofol required to maintain surgical plane of anesthesia \\
1 (Fair) & One or 2 additional bolus IV doses of propofol (within a period of 5 min) to control movement after the first 20 min \\
2 (Good) & Appeared to be in light plane of anesthesia; responded to a bolus IV injection of propofol \\
3 (Excellent) & Smooth anesthetic period; depth of anesthesia responded to increase or decrease in propofol infusion rate \\
\hline Anesthetic recovery & \\
0 (Unable to stand) & Horse cannot stand for >2 hr after multiple attempts to stand; excitement is evident; injury or high risk of injury \\
1 (Poor) & Multiple attempts to stand; excitement is evident; high risk of injury \\
2 (Fair) & Multiple attempts to stand; substantial ataxia \\
3 (Satisfactory) & Stands after 1 to 3 attempts; prolonged ataxia but no excitement \\
4 (Good) & Stands after 1 or 2 attempts; mild, short-term ataxia \\
5 (Excellent) & Stands after first attempt; no ataxia \\
\hline
\end{tabular}

and systemic vascular resistance (SVR; dynes $/ \mathrm{sec} / \mathrm{cm}^{5}$ ) were calculated using standard formulas [27]. Arterial blood samples were anaerobically collected from the dorsal metatarsal artery into heparinized syringes for immediate blood gas $\left(\mathrm{PaO}_{2}\right.$ and $\left.\mathrm{PaCO}_{2}\right)$ and $\mathrm{pH}$ analysis (Rapidlab 348; Bayer Medical Co., Tokyo, Japan).

Measurements of plasma propofol concentration: Arterial blood samples $(8 \mathrm{ml})$ were collected from the catheter placed in the dorsal metatarsal artery at selected time intervals for determination of plasma propofol concentration. The selected sampling times were: just before skin incision, 30 and 60 min after beginning surgery, at the end of surgery, at end of propofol infusion, $10 \mathrm{~min}$ after the cessation of propofol infusion, after removal of the endotracheal tube and just after the horses regained a standing position.

Plasma concentration $(\mathrm{Cpl})$ of propofol was determined by high performance liquid chromatography (HPLC) using fluorescence detection [25, 32]. The blood samples were mixed with heparine sodium (10 unit per $1 \mathrm{ml}$ of blood) and centrifuged $(1,580 \times g$ for $15 \mathrm{~min})$ immediately to separate plasma. Then, the plasma samples were stored at $-80^{\circ} \mathrm{C}$. Each plasma sample $(200 \mu l)$ was mixed with $100 \%$ methanol $(400 \mu l)$ and the top clear layer $(300 \mu l)$ extracted after centrifugation $(1,580 \times g$ for $15 \mathrm{~min})$. Another $100 \%$ methanol $(400 \mu l)$ was mixed with the precipitate and the top clear layer $(300 \mu l)$ again separated by centrifugation. These extracts were combined, and $200 \mu l$ of the extract was mixed with purified water $(600 \mu l)$ and stored at $-80^{\circ} \mathrm{C}$ until HPLC analysis.
The instruments using HPLC analysis consisted of dual pumps (DP-8020; Tosoh Co.), auto-sampler (AS-8020; Tosoh Co.), reversed-phase column (TSK-GEL ODS-80TS; Tosoh Co.), integration software (LC8020; Tosoh Co.), degasser (GASTORR 702; Eyela Co.) and intelligent fluorescence detector (FP-2020 plus; JASCO Co., Tokyo, Japan). Propofol within each extract sample was separated with the reversed-phase column using a linear gradient mobile phase from methanol-water-ammonium acetate (24: 75.94: 0.06) to $100 \%$ methanol delivered at $1 \mathrm{ml} / \mathrm{min}$ and detected by the fluorescence detector set at $276 \mathrm{~nm}$ (excitation) and $310 \mathrm{~nm}$ (emission). The limit of detection for propofol was $0.05 \mu \mathrm{g} /$ $\mathrm{m} l$. The apparent elimination half-life (terminal half-life: $\mathrm{t}^{1 / 2}$ ) was calculated from the terminal log-linear portion of the post-infusion propofol plasma decay curve.

Evaluation of quality of anesthesia and recovery: The quality of anesthetic induction, transition to TIVA (the first $20 \mathrm{~min}$ of anesthesia), anesthetic maintenance (from the first $20 \mathrm{~min}$ to the end of anesthesia i.e drug infusions stopped) and recovery from anesthesia were evaluated using scoring system [30] (Table 1). The times from the cessation of anesthesia to extubation, first movement, sternal position and standing were recorded.

Statistical analysis: Data are expressed as mean \pm SD. A repeated measures ANOVA was used to compare changes in cardiovascular and respiratory data. A Student paired $t$-test was used to determine differences between time points when appropriate. Differences were considered significant when $P<0.05$. 

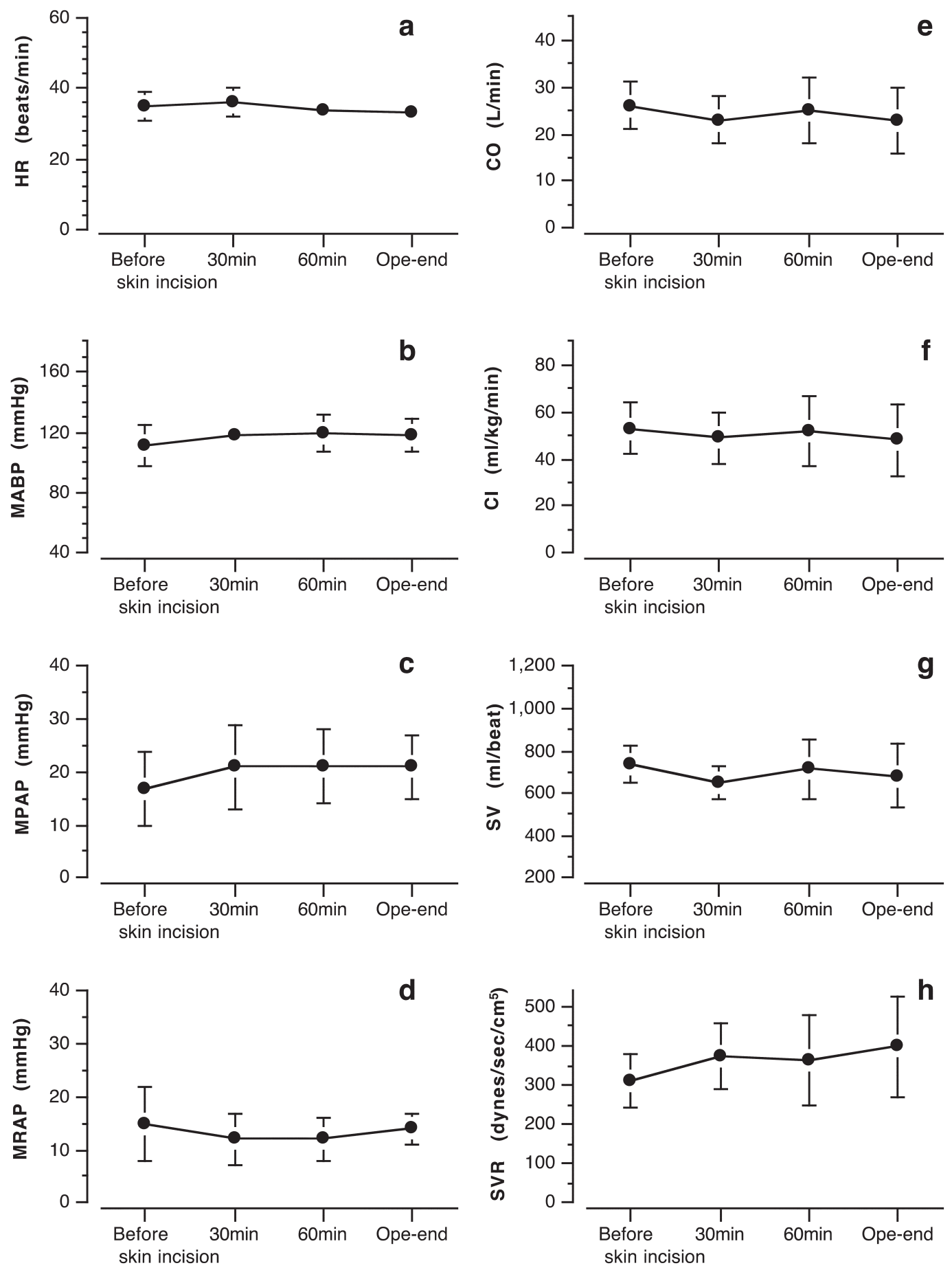

Fig. 1. Cardiovascular values during surgery in 5 horses undergoing KMP-TIVA. Plots and error bars showed mean value and standard deviation from 5 horses, respectively. HR: heart rate, MABP: mean arterial blood pressure, MPAP: mean pulmonary artery pressure, MRAP: mean right atrial pressure, CO: cardiac output, CI: cardiac index, SV: stroke volume, SVR: systemic vascular resistance, Before skin incision: just before skin incision, $30 \mathrm{~min}: 30 \mathrm{~min}$ into surgery, $60 \mathrm{~min}$ : $60 \mathrm{~min}$ into surgery, Ope-end: at the end of operation. 
Table 2. Respiratory rate, blood gas values and arterial $\mathrm{pH}($ mean $\pm \mathrm{SD})$ in 5 horses on IPPV undergoing carotid artery translocation via KMP-TIVA

\begin{tabular}{lccccc}
\hline Variable & Pre value & Before skin incision & $30 \mathrm{~min}$ & $60 \mathrm{~min}$ & Ope-end \\
\hline $\mathrm{RR}($ breaths $/ \mathrm{min})$ & $15 \pm 3$ & $6 \pm 0$ & $6 \pm 0$ & $6 \pm 0$ & $6 \pm 0$ \\
$\mathrm{pHa}$ & $\mathrm{ND}$ & $7.45 \pm 0.04$ & $7.46 \pm 0.04$ & $7.47 \pm 0.04$ & $7.48 \pm 0.05$ \\
$\mathrm{PaCO}_{2}(\mathrm{mmHg})$ & $\mathrm{ND}$ & $54 \pm 5$ & $51 \pm 7$ & $51 \pm 7$ & $49 \pm 6$ \\
$\mathrm{PaO}_{2}(\mathrm{mmHg})$ & $\mathrm{ND}$ & $598 \pm 127$ & $581 \pm 115$ & $589 \pm 109$ & $617 \pm 111$ \\
\hline
\end{tabular}

Data showed mean \pm standard deviation from 5 horses. Pre value was measured before any medications were administered. ND: Not determined. Before skin incision: Just before skin incision, $30 \mathrm{~min}$ : $30 \mathrm{~min}$ into surgery, $60 \mathrm{~min}: 60 \mathrm{~min}$ into surgery, Ope-end: At the end of operation. RR: Respiratory rate, $\mathrm{pHa}$ : Arterial blood $\mathrm{pH}, \mathrm{PaCO}_{2}$ : Partial pressure of arterial carbon dioxide. $\mathrm{PaO}_{2}$ : Partial pressure of arterial oxygen.

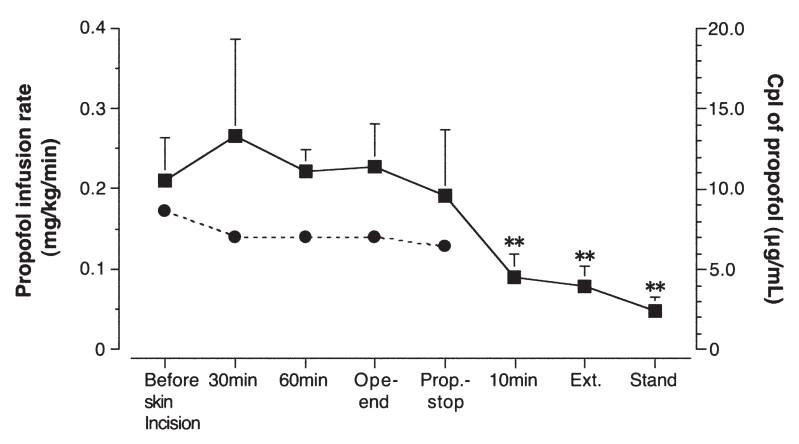

Fig. 2. Propofol infusion rates and plasma concentration $(\mathrm{Cpl})$ in 5 horses undergoing KMP-TIVA. Closed circles showed mean value of propofol infusion rates from 5 horses. Closed squares and error bars showed mean value of $\mathrm{Cpl}$ and its standard deviation, respectively. Values significantly $(* * P<0.01)$ lower than the $\mathrm{Cpl}$ of propofol at the end of operation. Before skin incision (just before skin incision); $30 \mathrm{~min}$ (30 min after beginning surgery); $60 \mathrm{~min}$ (60 min after beginning surgery); Ope-end (at the end of operation); Prop.-stop (at the end of propofol infusion); $10 \mathrm{~min}$ (10 min after cessation of propofol administration), Ext (just after extubation); Stand (just after the horses stood).

\section{RESULTS}

Cardiovascular effects: Cardiovascular parameters were stable and preserved within normal limits for anesthetized horses (Fig. 1). Mean values of HR ranged from 33 to 37 beats/min, and mean ABP (MABP) ranged from 111 to $119 \mathrm{mmHg}$ in all horses. CI and SV values ranged from 48 to $53 \mathrm{ml} / \mathrm{kg} / \mathrm{min}$ and from 650 to $800 \mathrm{~m} / /$ beat during surgery, respectively. SVR ranged from 311 to 398 dynes $/ \mathrm{sec} / \mathrm{cm}^{5}$. Mean PAP (MPAP) and mean RAP (MRAP) ranged from 17 to $21 \mathrm{mmHg}$ and from 12 to $15 \mathrm{mmHg}$ during surgery, respectively (Fig. 1).

Respiration and arterial blood gases: The mean time after induction of anesthesia to the start of IPPV was 15.8 \pm 2.9 min. The $\mathrm{PaCO}_{2}$ and $\mathrm{PaO}_{2}$ were maintained at 49 to $54 \mathrm{mmHg}$ and 581 to $617 \mathrm{mmHg}$, throughout anesthesia, respectively (Table 2).

Propofol infusion rate and plasma concentration: The CRI of propofol ranged from $0.17 \pm 0.01 \mathrm{mg} / \mathrm{kg} / \mathrm{min}$ before skin incision to $0.13 \pm 0.01 \mathrm{mg} / \mathrm{kg} / \mathrm{min}$ at the time of cessation of propofol infusion (Fig. 2). Propofol Cpl was 10.6

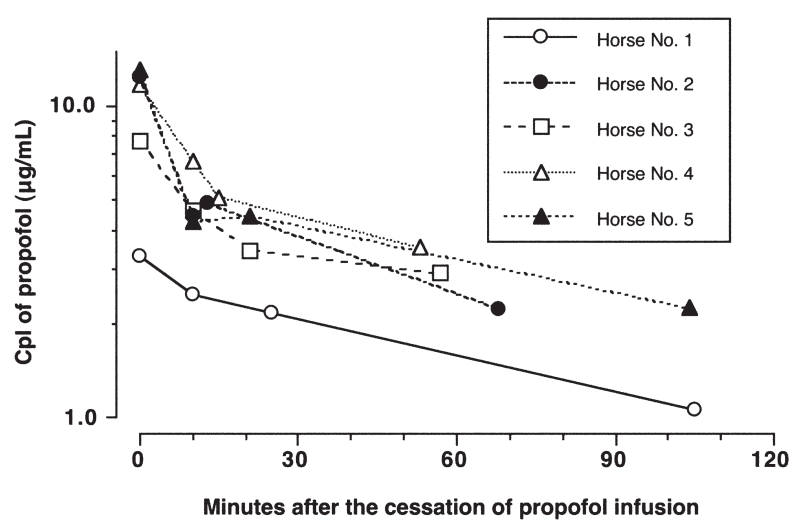

Fig. 3. Semilogarithmic plots of propofol plasma concentration (Cpl) versus time after the cessation of propofol infusion in individual 5 horses anesthetized with KMP-TIVA for surgery. The terminal half-life of propofol $\left(\mathrm{t}^{1} / 2\right)$ was estimated to be $80 \mathrm{~min}$ for Horse No.1, 68 min for Horse No.2, 85 min for Horse No.3, 50 min for Horse No.4 and 100 min for Horse No.5 (mean \pm SD: $76.6 \pm$ $18.8 \mathrm{~min}$ ).

$\pm 2.6 \mu \mathrm{g} / \mathrm{m} l$ just before skin incision, $13.3 \pm 6.0 \mu \mathrm{g} / \mathrm{m} l$ at $30 \mathrm{~min}, 11.1 \pm 1.4 \mu \mathrm{g} / \mathrm{m} l$ at $60 \mathrm{~min}$ and $11.4 \pm 2.7 \mu \mathrm{g} / \mathrm{ml}$ at the end of surgery. The propofol $\mathrm{Cpl}$ declined rapidly after cessation of propofol infusion. The propofol $\mathrm{Cpl}$ was significantly decreased $(P<0.01)$ at $10 \mathrm{~min}$ after the cessation of KMP-TIVA $(4.5 \pm 1.5 \mu \mathrm{g} / \mathrm{m} l)$, extubation $(4.0 \pm 1.2 \mu \mathrm{g} /$ $\mathrm{m} l)$ and after standing $(2.4 \pm 0.9 \mu \mathrm{g} / \mathrm{m} l)$ compared to the end of surgery. The $\mathrm{t}^{1} / 2$ for propofol was estimated to be $76.6 \pm$ 18.8 min (Fig. 3).

Quality of anesthesia and anesthetic events: Induction to anesthesia was smooth and excitement-free with adequate muscle relaxation (score 4) in all horses. All horses became recumbent within 1-2 min from the time of ketaminemidazolam administration. There were no limb movements and/or head shaking after becoming recumbent. Transition to the KMP-TIVA was uneventful (score 3) in all horses. The horses remained anesthetized for $175 \pm 14 \mathrm{~min}$ (range from 160 to $197 \mathrm{~min}$ ). The quality of anesthesia was considered to be excellent (score 3 ) in all horses. The times to extubation, first movement and sternal recumbency were $19 \pm 5$ (ranged from 13 to 25 ) $\mathrm{min}, 15 \pm 8$ (ranged from 5 to 24) $\mathrm{min}$ and 65 \pm 29 (ranged from 38 to 99 ) min, respectively. The number 
of attempts to stand and time to standing after the cessation of KMP-TIVA were $1.2 \pm 0.4$ (ranged from 1 to 2 ) and 74 \pm 28 (ranged from 42 to 105 ) $\mathrm{min}$, respecively. The quality of recovery from anesthesia was judged to be excellent or good, and recovery was uneventful. One horse had a recovery score of 5 (excellent), whereas 4 horses had a recovery score of 4 (good).

\section{DISCUSSION}

The administration of KMP-TIVA produced stable and satisfactory anesthesia for surgery in all our horses. Cardiovascular function in the horses remained within acceptable ranges for healthy resting horses [27], and hypoventilation and hypoxia were effectively prevented by IPPV. The recovery from KMP-TIVA was uneventful, and its quality was excellent to good. However, the longer duration of anesthesia resulted in longer recovery, although the propofol $\mathrm{Cpl}$ declined rapidly after the cessation of anesthesia.

Nolan and Hall [23] conjectured that the $95 \%$ of effective dose of propofol to prevent a response to surgical stimulus for horses might be greater than $0.28 \mathrm{mg} / \mathrm{kg} / \mathrm{min}$ when horses are anesthetized with propofol alone. The propofol infusion rates required to maintain surgical anesthesia ranged from $0.18 \pm 0.04 \mathrm{mg} / \mathrm{kg} / \mathrm{min}$ to $0.22 \pm 0.03 \mathrm{mg} / \mathrm{kg} / \mathrm{min}$ in horses premedicated with $\alpha_{2}$-adrenoceptor agonists and induced to anesthesia with either midazolam $(0.04 \mathrm{mg} / \mathrm{kg}$ IV) and ketamine (2.5 mg/kg IV) or propofol (2 mg/kg IV) [23, 30]. We were able to achieve, an excellent surgical plane of anesthesia with a lower infusion rate of propofol $(0.13 \mathrm{mg} / \mathrm{kg} / \mathrm{min})$ in horses anesthetized with KMP-TIVA, and this finding is similar to our previous report in horses anesthetized with KMP-TIVA for the surgical translocation of their carotid artery [30]. The reduction in propofol requirements is most likely due to the anesthetic and analgesic interactive effects of propofol when combined with ketamine and medetomidine. Ketamine, a dissociative anesthetic drug, induces analgesia by antagonizing N-methyl-D-aspartate (NMDA) receptors [14]. Medetomidine is an $\alpha_{2}$-adrenoceptor agonist that activates $\alpha_{2}$-receptors located in the spinal cord and brain stem, resulting in sedation and analgesia [8].

To determine pharmacokinetic parameters, plasma concentrations of drugs are usually measured, because plasma is more readily handled and stored than blood. However, blood levels of propofol were measured in previous reports $[10,24]$, because the measurement of the drug in plasma is reported to yield propofol concentrations lower than in blood, indicating that propofol is more intimately associated with the red blood cells. On the other hand, plasma concentration monitoring is recommended during propofol infusion, but immediate centrifugation is needed [9]. In the present study, we recorded somewhat higher propofol concentrations (11 to $13 \mu \mathrm{g} / \mathrm{m} l)$ compared with previous studies that reported the blood concentration of propofol ranged from 2.26 to $6.45 \mu \mathrm{g} /$ $\mathrm{m} l$ [24] and 3.27 to $9.44 \mu \mathrm{g} / \mathrm{ml}$ [10] during $60 \mathrm{~min}$ infusion of propofol in ponies. The plasma propofol concentrations at extubation and standing in the present study were also higher than the values obtained in the previous reports $[10,24]$.
Those reports $[10,24]$ were carried out in ponies, weighing 85 to $196 \mathrm{~kg}$ and 250 to $280 \mathrm{~kg}$, while the study reported here was investigated in thoroughbred, weighing 428 to 564 $\mathrm{kg}$. This difference may influence the pharmacokinetics and pharmacodynamics of propofol. Furthermore, it was pointed out that the concentration of propofol could be underestimated when whole blood was used during propofol infusion because plasma concentrations of propofol remained $30 \%$ higher than whole blood concentrations [9].

The $\mathrm{t}^{1 / 2}$ for propofol was reported to be $69.0 \pm 8.0 \mathrm{~min}$ in ponies premedicated with detomidine $20 \mu \mathrm{g} / \mathrm{kg}$ IV, given ketamine $2.2 \mathrm{mg} / \mathrm{kg}$ IV for induction of anesthesia, followed by a bolus injection of propofol $0.5 \mathrm{mg} / \mathrm{kg}$ IV and maintained with an infusion of propofol at $0.136 \mathrm{mg} / \mathrm{kg} / \mathrm{min}$ for $60 \mathrm{~min}$ and ketamine at $3 \mathrm{mg} / \mathrm{kg} / \mathrm{min}$ for $45 \mathrm{~min}$ [24]. These ponies stood up at $30.0 \pm 20.8 \mathrm{~min}$ after the cessation of anesthesia [24]. Smooth and satisfactory recovery after castration was also reported in ponies premedicated with detomidine $20 \mu \mathrm{g} / \mathrm{kg} \mathrm{IV}$, given ketamine $2.2 \mathrm{mg} / \mathrm{kg}$ IV for induction of anesthesia, followed by a bolus injection of propofol $0.5 \mathrm{mg} / \mathrm{kg} \mathrm{IV}$ and maintained with an infusion of propofol at $0.124 \mathrm{mg} / \mathrm{kg} / \mathrm{min}$ and ketamine at $2.4 \mathrm{mg} / \mathrm{kg} / \mathrm{min}$ for $60 \mathrm{~min}$ [10]. These ponies stood up at $14.9 \pm 10.1 \mathrm{~min}$ after the cessation of anesthesia [10]. Compared to these reports in ponies, the recovery was longer in our horses anesthetized with KMP-TIVA for about $3 \mathrm{hr}$. On the other hand, the Cpl of propofol declined rapidly after the cessation of KMP-TIVA, and the estimated $t^{1} / 2$ of propofol in the present study (76.6 $\pm 18.8 \mathrm{~min}$ ) is similar to that reported in a previous study in ponies [24]. The duration of propofol infusion may not affect the clearance of propofol after the cessation of infusion in horses. The longer duration of KMP-TIVA might induce larger degrees of accumulation of ketamine and medetomidine, thus influencing rate of recovery from anesthesia in the present study.

Systemic hypotension and hypotensive events, MABP $<50$ to $60 \mathrm{mmHg}$, are responsible for most drug-related complications in anesthetized horses [7, 11, 15, 21, 36]. Marked reductions in MABP and tissue blood flow (CO) are responsible for the development of myopathy, myositis, rhabdomyolysis, spinal cord ischemia and degeneration, spinal cord malacia, cerebral necrosis, transient or permanent blindness, acute cardiac collapse and prolonged recovery from anesthesia [7, 11, 15, 21, 36]. Alternatively, MABP values in excess of $70 \mathrm{mmHg}$ during anesthesia are considered to be important for preventing post-operative myopathy in horses $[7,11,15,21,36]$. In the present study, the MABP ranged from 111 to $118 \mathrm{mmHg}$ during surgery and other cardiovascular parameters, except for the SVR remained within acceptable ranges for healthy resting horses [27]. Mean \pm standard deviation of SVR in standing, conscious, unsedated healthy resting horses are $262.4 \pm 63.4$ and $265 \pm 81$ dynes/ $\mathrm{sec} / \mathrm{cm}^{5}$ [27]. The SVR during KMP-TIVA mildly increased and was ranged around its upper limit for the healthy resting horses [27]. This mild increase in SVR and preserved CO within the acceptable range contributed to the good ABP in the horses anesthetized with KMP-TIVA for surgery. KMPTIVA provided a minimum cardiovascular depression in 
horses undergoing surgery.

Surgical stimulation causes stress and adrenergic responses resulting increases in HR and ABP when anesthetic and/or analgesic level is insufficient in patients. In the present study, the cardiovascular changes throughout anesthesia were similar to our previous report in horses anesthetized with KMP-TIVA for $4 \mathrm{hr}$ without surgical stimulation [31]. Therefore, the adrenergic response to surgical stimulation seemed to be completely controlled in our horses. It has been demonstrated that TIVA using a combination of detomidine, an $\alpha_{2}$-adrenoceptor agonist, ketamine and guaifenesin caused less cardiorespiratory depression than halothane anesthesia and reduced stress as suggested by decreases in plasma arginine vasopressin, $\beta$-endorphin, $\mathrm{ACTH}$, cortisol and catecholamine concentrations during anesthesia [16, 29]. Medetomidine has a greater selectivity of $\alpha_{2}$-adrenoceptors and comparative behavioral and neurochemical effects that suggest less endocrine changes during prolonged anesthesia in horses $[5,8,33]$. Ketamine produces an apparent analgesia by antagonizing NMDA receptors [14]. We inferred that KMP-TIVA provided sufficient anesthesia and analgesia and produced reduction of the stress induced by surgical stimulation.

Most spontaneously breathing horses hypoventilate during anesthesia. Drug-induced decreases in respiratory rate or tidal volume produce hypercarbia, which can result in respiratory acidosis and, when severe, can produce hypoxemia and lactic acidosis [21]. The maximum value that the $\mathrm{PaCO}_{2}$ should be allowed to increase before instituting controlled ventilation remains controversial [26]. $\mathrm{PaCO}_{2}$ values greater than $70 \mathrm{mmHg}$ may activate the central nervous system, making it more difficult to maintain a stable plane of anesthesia [21]. Initiating controlled ventilation early during the maintenance phase of anesthesia provides the best opportunity to prevent hypercarbia and maximize $\mathrm{PaO}_{2}[6,21]$. However, controlling ventilation may decrease $\mathrm{CO}$ and $\mathrm{ABP}$ secondary to increases in intrathoracic pressure, which can decrease venous return $[13,21]$. Our previous study demonstrated that horses administered KMP-TIVA and spontaneously breathing room air $\left(21 \% \mathrm{O}_{2}\right)$ developed hypercarbia $\left(\mathrm{PaCO}_{2}\right.$ range, 47 to $\left.77 \mathrm{mmHg}\right)$ and hyoxemia $\left(\mathrm{PaO}_{2}\right.$ range, 27 to $77 \mathrm{mmHg}$ ) shortly after induction of anesthesia [30]. That study and data from the current study suggest that hypoventilation may be a consequence of KMP-TIVA that hypercarbia and hypoxemia can be effectively prevented by IPPV and that cardiovascular function is maintained within acceptable limits for horses. Importantly, KMP-TIVA preserved cardiovascular function in horses even with controlled ventilation.

Our data demonstrated that induction of anesthesia with medetomidine-ketamine-midazolam and maintenance of anesthesia with KMP-TIVA provided satisfactory quality and control of anesthesia with minimum cardiovascular depression in horses undergoing surgery. However, the longer duration of KMP-TIVA may result in longer recovery.

ACKNOWLEDGMENT. Dr. Umar was supported by a study fellowship awarded by Monbukagakusho, Tokyo, Japan.

\section{REFERENCES}

1. Bettschart-Wolfensberger, R., Bowen, M. I., Freeman, S. L., Feller, R., Bettschart, R. W., Nolan, A. and Clarke, K. W. 2001. Cardiopulmonary effects of prolonged anesthesia via propofol-medetomidine infusion in ponies. Am. J. Vet. Res. 62: 1428-1435. [Medline] [CrossRef]

2. Bettschart-Wolfensberger, R., Bowen, M. I., Freeman, S. L., Weller, R. and Clarke, K. W. 2003. Medetomidine-ketamine anaesthesia induction followed by medetomidine-propofol in ponies: infusion rates and cardiopulmonary side effects. Equine Vet. J. 35: 308-313. [Medline] [CrossRef]

3. Bettschart-Wolfensberger, R., Freeman, S. L., Jäggin-Schmucker, N. and Clarke, K. W. 2001. Infusion of a combination of propofol and medetomidine for long-term anesthesia in ponies. Am. J. Vet. Res. 62: 500-507. [Medline] [CrossRef]

4. Bettschart-Wolfensberger, R., Kalchofner, K., Neges, K., Kästner, S. and Fürst, A. 2005. Total intravenous anesthesia in horses using medetomidine and propofol. Vet. Anaesth. Analg. 32: 348-354. [Medline] [CrossRef]

5. Bryant, C. E., England, G. C. W. and Clarke, K. W. 1991. Comparisons of the sedative effects of medetomidine and xylazine in horses. Vet. Rec. 129: 421-423. [Medline] [CrossRef]

6. Day, T. K., Gaynor, J. S., Muir, W. W. 3rd., Bednarski, R. M. and Mason, D. E. 1995. Blood gas values during intermittent positive pressure ventilation and spontaneous ventilation in 160 anesthetized horses positioned in lateral or dorsal recumbency. Vet. Surg. 24: 266-276. [Medline] [CrossRef]

7. Duke, T., Filzek, U., Read, M. R., Read, E. K. and Ferguson, J. G. 2006. Clinical observation surrounding an increased incidence of postanesthetic myopathy in halothane-anesthetized horses. Vet. Anaesth. Analg. 33: 122-127. [Medline] [CrossRef]

8. England, G. C. W. and Clarke, K. W. 1996. Alpha 2 adrenoceptor agonists in the horse - a review. Br. Vet. J. 152: 641-657. [Medline] [CrossRef]

9. Fan, S. Z., Yu, H. Y., Chen, Y. L. and Liu, C. C. 1995. Propofol concentration monitoring in plasma or whole blood by gas chromatography and high-perfomance liquid chromatography. Anesth. Analg. 81: 175-178. [Medline]

10. Flaherty, D., Reid, J., Welsh, E., Monteiro, A. W., Lerche, P. and Nolan, A. 1997. A pharmacodynamic study of propofol or propofol and ketamine in ponies undergoing surgery. Res. Vet. Sci. 62: 179-184. [Medline] [CrossRef]

11. Grandy, J. L., Steffey, E. P., Hodgson, D. S. and Woliner, M. J. 1987. Arterial hypotension and the development of postanesthetic myopathy in halothan-anesthetized horses. Am. J. Vet. Res. 48: 192-197. [Medline]

12. Greene, S. A., Thurmon, J. C., Tranquilli, W. J. and Benson, G. J. 1986. Cardiopulmonary effects of continuous intravenous infusion of guaifenesin, ketamine, and xylazine in ponies. Am. J. Vet. Res. 47: 2364-2367. [Medline]

13. Hodgson, D. S., Steffey, E. P., Grandy, J. L. and Woliner, M. J. 1986. Effects of spontaneous, assisted, and controlled ventilatory modes in halothane-anesthetized geldings. Am. J. Vet. Res. 47: 992-996. [Medline]

14. Klepstad, P., Maurset, A., Moberg, E. R. and Oye, I. 1990. Evidence of a role for NMDA receptors in pain perception. Eur. $J$. Pharmacol. 187: 513-518. [Medline] [CrossRef]

15. Lindsay, W. A., Robinson, G. M., Brunson, D. B., Brunson, D. B. and Majors, L. J. 1989. Induction of equine postanesthetic myositis after halothane-induced hypotension. Am. J. Vet. Res. 50: 404-410. [Medline]

16. Luna, S. P. L., Taylor, P. M. and Wheeler, M. J. 1996. Cardiore- 
spiratory, endocrine and metabolic changes in ponies undergoing intravenous or inhalation anesthesia. J. Vet. Pharmacol. Ther. 19: 251-258. [Medline] [CrossRef]

17. Mama, K. R., Pascoe, P. J., Steffey, E. P. and Kollias-Baker, C. 1998. Comparison of two techniques for total intravenous anesthesia in horses. Am. J. Vet. Res. 59: 1292-1298. [Medline]

18. Mama, K. R., Steffey, E. P. and Pascoe, P. J. 1995. Evaluation of propofol as a general anesthetic for horses. Vet. Surg. 24: 188-194. [Medline] [CrossRef]

19. Mama, K. R., Wagner, A. E., Steffey, E. P., Kollias-Baker, C., Hellyer, P. W., Golden, A. E. and Brevard, L. F. 2005. Evaluation of xylazine and ketamine for total intravenous anesthesia in horses. Am. J. Vet. Res. 66: 1002-1007. [Medline] [CrossRef]

20. Matthews, N. S., Hartsfield, S. M., Hague, B., Carroll, G. L. and Short, C. E. 1999. Detomidine-propofol anesthesia for abdominal surgery in horses. Vet. Surg. 28: 196-201. [Medline] [CrossRef]

21. Muir, W. W. and Hubbell, J. A. E. 2009. Anesthetic-associated complications. pp. 397-417. In: Equine Anesthesia: Monitoring and Emergency Therapy, 2nd ed. (Muir, W. W. and Hubbell, J. A. E. eds.), Mosby-Year Book, St. Louis.

22. Muir, W. W., Skarda, R. T. and Milne, D. W. 1976. Estimation of cardiac output in the horse by thermodilution techniques. Am. J. Vet. Res. 37: 697-700. [Medline]

23. Nolan, A. M. and Hall, L. W. 1985. Total intravenous anaesthesia in the horse with propofol. Equine Vet. J. 17: 394-398. [Medline] [CrossRef]

24. Nolan, A., Reid, J., Welsh, E., Flaherty, D., McComack, R. and Monteiro, A. M. 1996. Simultaneous infusions of propofol and ketamine in ponies premedicated with detomidine: a pharmacokinetic study. Res. Vet. Sci. 60: 262-266. [Medline] [CrossRef]

25. Plummer, G. F. 1987. Improved method for the determination of propofol in blood by high-performance liquid chromatography with fluorescence detection. J. Chromatogr. 421: 171-176. [Medline] [CrossRef]

26. Rogovik, A. and Goldman, R. 2008. Permissive hypercapnia. Emerg. Med. Clin. North Am. 26: 941-952. [Medline] [CrossRef]

27. Schwartzward, C. C., Bonagura, J. D. and Muir, W. W. 2009. The cardiovascular system. pp. 37-100. In: Equine Anesthesia: Monitoring and Emergency Therapy, 2nd ed. (Muir, W. W. and
Hubbell, J. A. E. eds.), Mosby-Year Book, St. Louis.

28. Steffey, E. P. and Howland, D. 1980. Comparison of circulatory and respiratory effects of isoflurane and halothane anaesthesia in horses. Am. J. Vet. Res. 41: 821-825. [Medline]

29. Taylor, P. M., Luna, S. P. L., Sear, J. W. and Wheeler, M. J. 1995. Total intravenous anesthesia in ponies using detomidine, ketamine and guaifenesin: pharmacokinetics, cardiopulmonary and endocrine effects. Res. Vet. Sci. 59: 17-23. [Medline] [CrossRef]

30. Umar, M. A., Yamashita, K., Kushiro, T. and Muir, W. W. 2006. Evaluation of total intravenous anesthesia with propofol or ketamine-medetomidine-propofol combination in horses. $\mathrm{J}$. Am. Vet. Med. Assoc. 228: 1221-1227. [Medline] [CrossRef]

31. Umar, M. A., Yamashita, K., Kushiro, T. and Muir, W. W. 2007. Evaluation of cardiovascular effects of total intravenous anesthesia with propofol or a combination of ketamine-medetomidine-propofol in horses. Am. J. Vet. Res. 68: 121-127. [Medline] [CrossRef]

32. Yamashita, K., Akashi, N., Katayama, Y., Uchida, Y., Umar, M. A., Itami, T., Inoue, H., Sams, R. A. and Muir, W. W. 2009. Evaluation of bispectral index (BIS) as an indicator of central nervous system depression in horses anesthetized with propofol. J. Vet. Med. Sci. 71: 1465-1471. [Medline] [CrossRef]

33. Yamashita, K., Kishihara, K., Haramaki, S., Tsukiyama, K., Tagami, M., Izumisawa, Y. and Kotani, T. 1999. Comparison of the sedative effects of medetomidine, detomidine and xylazine in horses. J. Jpn. Vet. Med. Assoc. 52: 498-503 (in Japanese with English summary). [CrossRef]

34. Yamashita, K. and Muir, W. W. 2009. Intravenous anesthetic and analgesic adjuncts to inhalation anesthesia. pp. 260-276. In: Equine Anesthesia: Monitoring and Emergency Therapy, 2nd ed. (Muir, W. W. and Hubbell, J. A. E. eds.), Mosby-Year Book, St. Louis.

35. Yamashita, K., Wijayathilaka, T. P., Kushiro, T., Umar, M. A., Taguchi, K. and Muir, W. W. 2007. Anesthetic and cardiopulmonary effects of total intravenous anesthesia using a midazolam, ketamine and medetomidine drug combination in horses. $J$. Vet. Med. Sci. 69: 7-13. [Medline] [CrossRef]

36. Young, S. S. and Taylor, P. M. 1993. Factors influencing the outcome of equine anesthesia: a review of 1,314 cases. Equine Vet. J. 25: 147-151. [Medline] [CrossRef] 